\title{
A Rare Cause of Anuria: A Case of Inflammatory Iliac Aneurysm
}

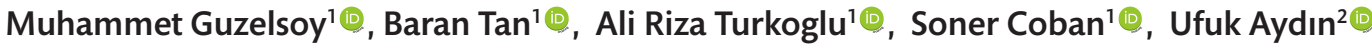 \\ 'Bursa YIEAH, Urology, Bursa, Turkey \\ 2Bursa YIEAH, Cardiovasculer surgery, Bursa, Turkey \\ Address for Correspondence: Muhammet Guzelsoy, E-mail: muhammetguzelsoy@yahoo.com.tr \\ Received: 04.09.2018; Accepted: 26.07.2018; Available Online Date: 23.01.2019 \\ (C) Copyright 2018 by Dokuz Eylül University, Institute of Health Sciences - Available online at www.jbachs.org
}

Cite this article as: Guzelsoy M, Tan B, Turkoglu AR, Coban S, Aydın U. A Rare Cause of Anuria: A Case Of Inflammatory Iliac Aneurysm. J Basic Clin Health Sci 2019; 3:35-38. https://doi. org/10.30621/jbachs.2019.428

\begin{abstract}
The patient was a 68-year-old male. The patient of complaint was anuria. There was no sense of urination. Abdominopelvic ultrasonography (USG) and abdominopelvic computed tomography (CT) without contrast revealed an empty bladder and the presence of bilateral hydroureteronephrosis. Aneurysms in the aorta and bilateral iliac arteries were detected. It caused bilateral hydroureteronephrosis via compressing "aneurysmal bilateral ureter". Creatinine was $4.97 \mathrm{mg} / \mathrm{dL}$, BUN $37 \mathrm{mg} / \mathrm{dL}, \mathrm{C}$ reactive protein (CRP) $193 \mathrm{mg} / \mathrm{L}$ and erythrocyte sedimentation rate (ESR) $99 \mathrm{~mm} / \mathrm{h}$. A double J stent was inserted on the right and a nephrostomy tube was placed on the left. The urea and creatinine levels returned to normal postoperatively. Urinary obstruction or anuria can develop due to a lot of reasons such as stricture, urolithiasis, clot, and malignancy or inflammation of peripheral organs and etc. Abdominal aortic aneurysm (AAA) or iliac artery aneurysm (IAA) is a very rare cause of urinary obstruction or anuria. Abdominal aortic aneurysm (AAA) and iliac artery aneurysm (IAA) are rare factors that can cause urological symptoms with an inflammatory or direct compressive effect. There have been very rarely reported as a cause of acute anuria. We present a case of acute anuria due to bilateral inflammatory iliac artery aneurysm.
\end{abstract}

Keywords: Anuria, bilateral hydroureteronephrosis, iliac aneurysm, inflammatory

\section{INTRODUCTION}

AAA is accompanied by iliac artery aneurysm (IAA) in 10-20\% of cases (1). Inflammatory aneurysms (IA) constitute $3-10 \%$ of all aortoiliac aneurysms. IAs can become symptomatic by causing neurological, gastrointestinal and urinary side effects due to inflammatory changes and pressure effects in the peri-aneurysmal tissues (2). Aneurysms have been reported to cause acute renal failure by mechanically compressing the ureter (3). Anuria with an inflammatory aneurysm is rare (4).

We present a case that developed bilateral ureteral obstruction and anuria due to bilateral inflammatory iliac artery aneurysm in this case report.

\section{CASE PRESENTATION}

The patient was a 68-year-old male. A history of DM, HT, smoking and bilateral open stone surgery was present. He had been suffering from mild blunt abdominal pain for the past year. An $8 \mathrm{~mm}$ stone had been found in the left kidney and conservative treatment suggested at the various health centers he had visited.
ESWL had been used at the health center he had recently gone to. Flexible URS had been performed for the residual stones and a double J stent inserted to both ureters. The patient presented to our institution three months later and the bilateral double J stents were then withdrawn. The patient had normal biochemical values but presented to our clinic with anuria 24 hours later. There was no sense of urination. Creatinine was $4.97 \mathrm{mg} / \mathrm{dL}, \mathrm{BUN} 37 \mathrm{mg} / \mathrm{dL}, \mathrm{C}$ reactive protein (CRP) $193 \mathrm{mg} / \mathrm{L}$ and erythrocyte sedimentation rate (ESR) 99 $\mathrm{mm} / \mathrm{h}$. USG and abdominopelvic CT without contrast revealed an empty bladder and the presence of bilateral hydroureteronephrosis (Figure 1). Aneurysms in the aorta and bilateral iliac arteries were detected. It caused bilateral hydroureteronephrosis via compressing "aneurysmal bilateral ureter" (Figure 2). The patient was urgently taken to surgery and a double J stent was inserted on the right. However, the J stent could not be inserted on the left due to angulation and a nephrostomy tube was placed. The urea and creatinine levels returned to normal postoperatively. CT with contrast revealed bilateral iliac aneurysm (38-37 mm) and aortic aneurysm $(50 \mathrm{~mm})$ compressing both ureters, and increased density of peri-iliac and aortic circumferential soft tissue. The 


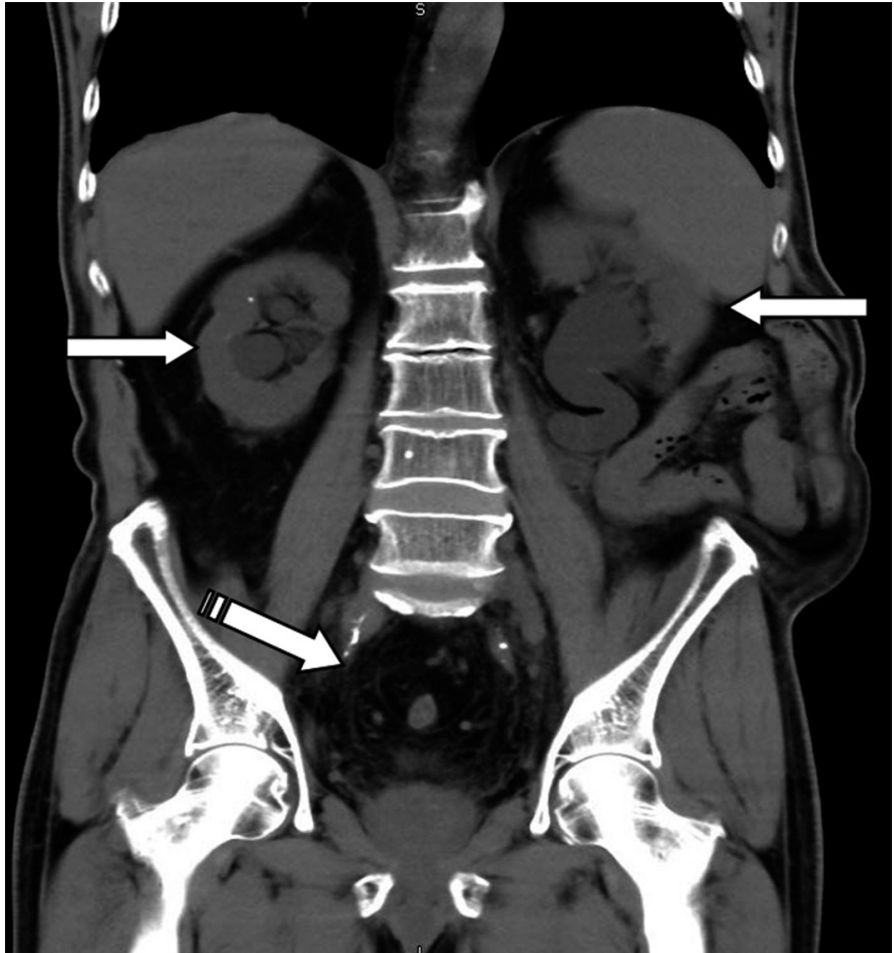

Figure 1. Empty bladder (striped arrow) and the presence of bilateral hydroureteronephrosis (white arrow)

bilateral iliac aneurysms were compressing bilateral ureters. There was double $\mathrm{J}$ stent on the right ureter and the nephrostomy tube on the left kidney. In addition, there was urine in the bladder (Figure 3). There was no evidence of aneurysm rupture on CT. The patient was recommended surgical or endovascular intervention for the aneurysm by the cardiovascular department but did not accept surgery and was therefore followed-up.

\section{DISCUSSION}

Urinary obstruction can develop due to a lot of intrinsic reasons such as stricture, bilateral urolithiasis, clot, foreign body and malignancy or inflammation of peripheral organs or acquired reasons such as surgery or radiotherapy. AAA or IAA is a very rare cause of anuria and is usually not primarily considered.

IAA usually coexists with AAA and is usually asymptomatic. IAA can cause mechanical obstruction at any level of the urinary tract and result in symptoms. IAA is a rare cause of postoperative uropathy (5). The condition is usually due to an increased aneurysm diameter obstructing the ureter mechanically (3). However, one must remember that it can also develop as a result of peri-aneurysmatic inflammatory changes, as in our patient (4). This type of inflammatory aneurysm makes up 3-10\% of aortoiliac aneurysms and is more common in males.

IA can become symptomatic by causing neurological, gastrointestinal and urinary side effects due to inflammatory changes and a pressure effect on the peri-aneurysmal tissues.

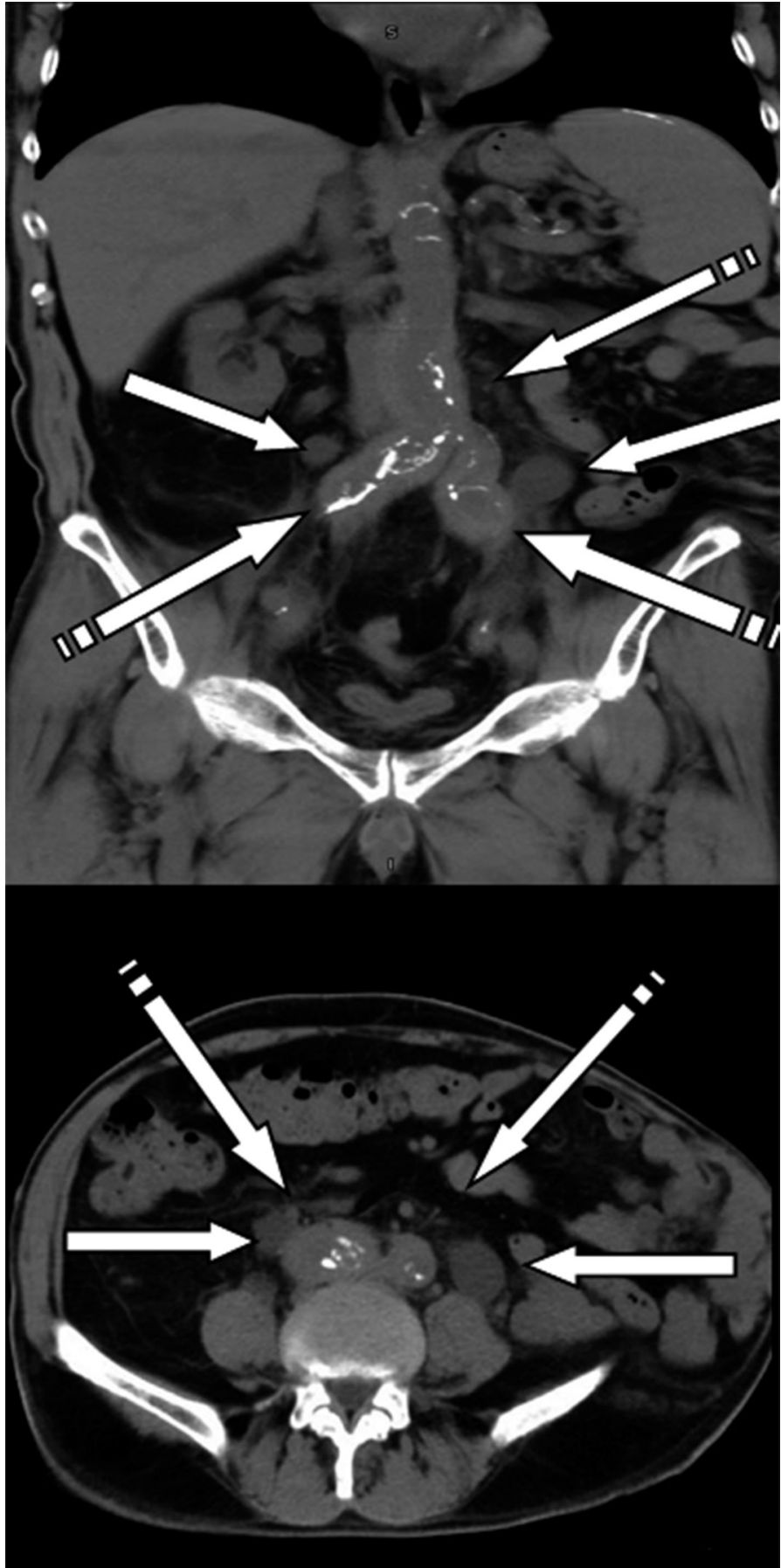

Figure 2. Bilateral hydroureteronephrosis (white arrow) and aneurysms in the aorta and bilateral iliac arteries (striped arrows).

Abdominal distension, ileus, lower abdominal pain and melena can develop due to sigmoid colon and rectum compression while back pain, thigh and hip pain, weakness and numbness of the feet can be the result of lumbosacral plexus compression. Urological symptoms occur when the bladder and ureter are affected and can be in the form of urinary retention or microscopic hematuria. Macroscopic hematuria usually suggests an ureteroiliac aneurysmal fistula and is fatal (6). Most of these patients have an increased erythrocyte sedimentation rate or laboratory findings of inflammation. The cause of this inflammation is not clear 

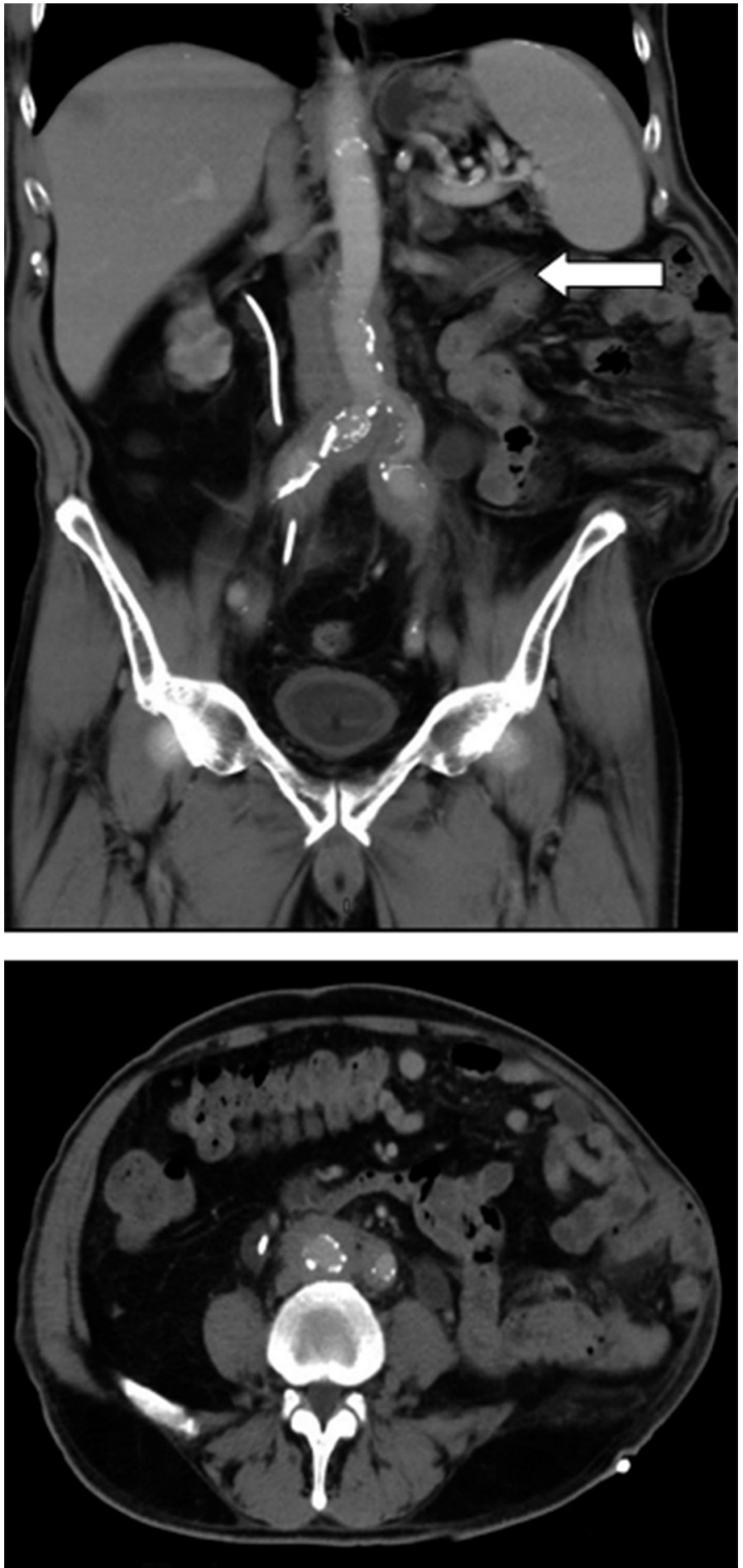

Figure 3. The bilateral iliac aneurysms were compressing the ureters and there was urine in the bladder. There were double J stent on the right ureter and the nephrostomy tube on the left kidney (white arrow). although there seems to be an immune response localized on the vessel wall. The condition is thought to be multifactorial with the interaction of genetic, autoimmune, infectious and environmental factors in addition to smoking and hypertension (7). Fever, weight loss, and high ESR and CRP indicate an inflammatory component of the aneurysm $(2,8)$.

Acute anuria and bilateral hydroureteronephrosis were observed in the presented case. The patient had aortic and bilateral iliac aneurysms. Although the aneurysm was not at a size that could cause mechanical compression, it still affected both ureters and caused acute anuria. This male patient had no relevant family history. He had not been smoking for a long time and the DM and HT were both under control. In other words, it is quite difficult to talk about a suspected etiological factor in our patient.

USG is usually the preferred investigation in such patients and is widely used. CT shows the peri-aneursymal soft tissue inflammation and its distribution perfectly. CT can show aneurysmal dilatation, a thickened aortic wall, and aortic mural thrombus and wall calcification with peri-aneurysmal fibrosis. Peri-aneurysmal soft tissue and inflammatory changes are seen with contrast enhancement and any pressure on peripheral tissues is clearly demonstrated $(4,7)$.

Ureter decompression is urgently needed in case of hydroureteronephrosis. Treatment options include open aneurysm surgery and endovascular stent interventions. Performing ureterolysis for the ureter obstruction is controversial due to the difficult dissection and high morbidity and mortality rates with open surgery $(2,9)$. A ureteral stent and, if necessary, percutaneous nephrostomy are recently being recommended. The recurrence rate is lower in patients who have been inserted a ureteral stent (10). Systemic steroid treatment is recommended by some authors and an improvement with steroid use for continued obstruction after catheter removal is reported (11).

The patient did not accept the procedure due to the possible high comorbidity and did not undergo aneurysm surgery or an endovascular intervention. The aneurysm was followed-up with a double J stent.

Peer-review: Externally peer-reviewed.

Author Contributions: Concept - MG, BT, ART; Design - MG, BT; Supervision - ART, UA Resources - BT, MG; Materials - BT; Data Collection and/or Processing - BT, SC; Analysis and/or Interpretation - SC, ART, UA, MG; Literature Search - MG, BT, ART; Writing Manuscript - MG, ART, UA; Critical Review - ART, UA, SC

Conflict of Interest: No conflict of interest was declared by the authors.

Financial Disclosure: The authors declared that this study has received no financial support. 


\section{REFERENCES}

1. Forsdahl SH, Singh K, Solberg S, Jacobsen BK. Risk factors for abdominal aortic aneuryms: a 7 years prospective study: the Tromso Study. Circulation 2009;119:2202-2208. [CrossRef]

2. Kashyap VS, Fang R, Fitzpatrick CM, Hagino RT. Caval and ureteral obstruction secondary to an inflammatory abdominal aortic aneurysm. J Vasc Surg 2003;38:1416-21. [CrossRef]

3. Morishita A, Tomioka H, Katahira S, Hoshino T, Hanzawa K. Open Surgery for Giant Bilateral Internal Iliac Artery Aneurysms with Compression of Neighboring Abdominal Structures: A Case Report. Ann Vasc Dis 2015;8:265-267. [CrossRef]

4. Galosi AB, Grilli Cicilioni C, Sbrollini G, Angelini A, Maselli G, Carbonari L. Inflammatory abdominal aortic aneurysm presenting as bilateral hydroureteronephrosis: A case report and review of literature. Arch Ital Urol Androl 2014;86:385-386. [CrossRef]

5. Mujtaba B, Jan MF. Answer to case of the month \#157: anuria in the supine position. Can Assoc Radiol J 2009;60:281-282. [CrossRef]
6. Meecham L, Koo V, Rajjayabun P. Uretero-iliac artery aneurysm fistula: A rare but fatal cause of haematuria. J Surg Case Rep 2012:16. [CrossRef]

7. Tang T, Boyle JR, Dixon AK, Varty K. Inflammatory Abdominal Aortic Aneurysms. Eur J Vasc Endovasc Surg 2005;29:353-362. [CrossRef]

8. Pennell RC, Hollier LH, Lie JT, et al. Inflammatory abdominal aortic aneurysms: a thirty-year review. J Vasc Surg 1985;2:859-869. [CrossRef]

9. Bonnet P, Vandenberg C, Limet R. Treatment of urological complications related to aortoiliac pathology and surgery. Eur J Vasc Endovasc Surg 2003;26:657-664. [CrossRef]

10. Nevelsteen A, Lacroix H, Stockx L, Baert L, Depuydt P. Inflammatory abdominal aortic aneurysm and bilateral complete ureteral obstruction: treatment by endovascular graft and bilateral ureteric stenting. Ann Vasc Surg 1999;13:222-224. [CrossRef]

11. Jetty $P$, Barber GG. Aortitis and bilateral ureteral obstruction after endovascular repair of abdominal aortic aneurysm. J Vasc Surg 2004;39:1344-1347. [CrossRef] 